\title{
Supplementary: A Bayesian Ensemble Data Assimilation to Constrain Model Parameters and Land Use Carbon Emissions
}

Sebastian Lienert ${ }^{1,2}$ and Fortunat Joos ${ }^{1,2}$

${ }^{1}$ Climate and Environmental Physics, Physics Institute, University of Bern, Bern, Switzerland

${ }^{2}$ Oeschger Centre for Climate Change Research, University of Bern, Bern, Switzerland.

Correspondence to: Sebastian Lienert (lienert@ climate.unibe.ch) 

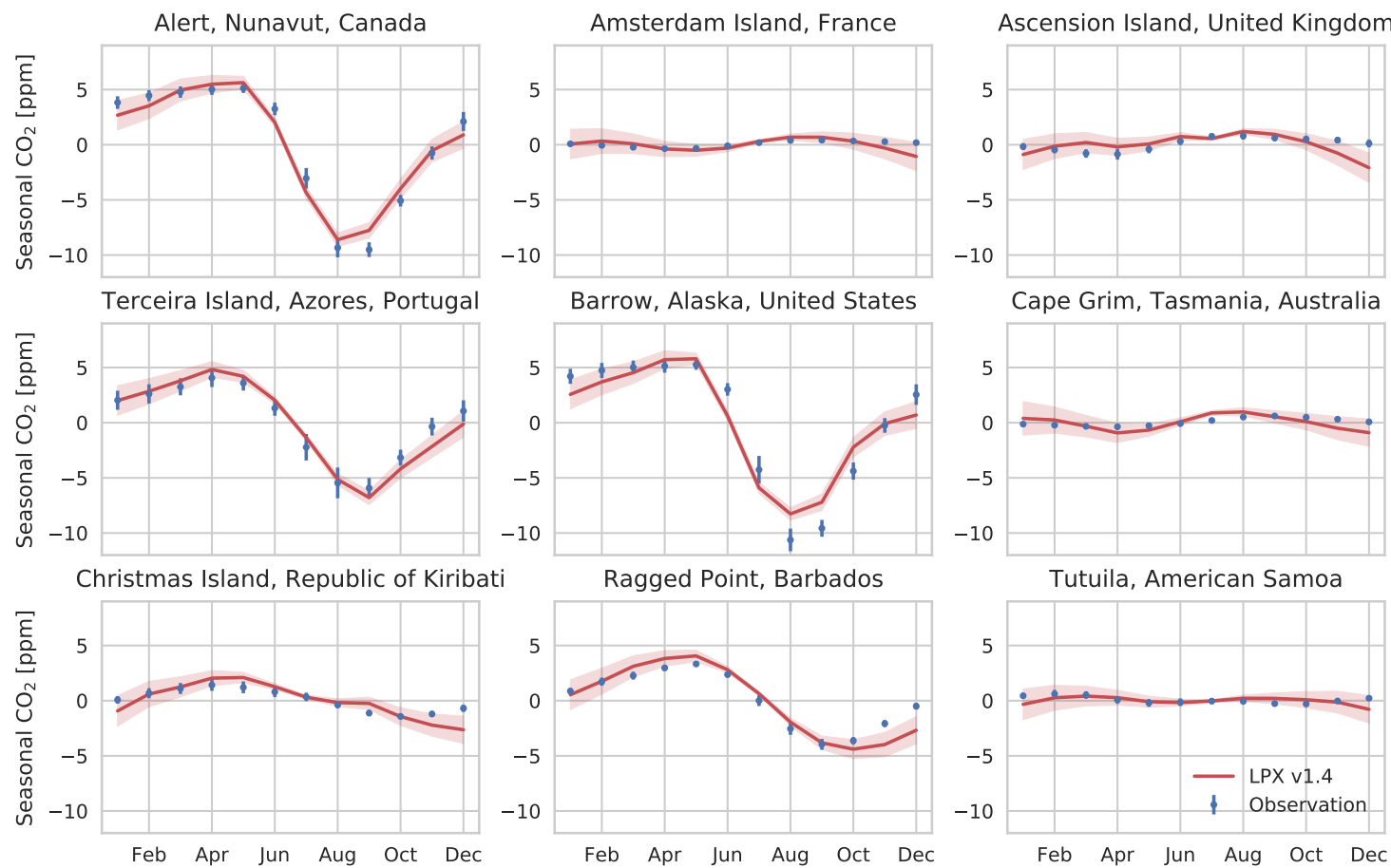

Figure S1. Seasonal cycle averaged from 1980 to 2013 at 9 measurement sites (GLOBALVIEW-CO2, 2013) (blue) compared to LPX v1.4 (red). The standard deviations are indicated with error bars or shading respectively. The seasonal cycle is computed with the TM2 transport model and simulated net surface-atmosphere fluxes from LPX v1.4 and the Bern3D ocean model (Battaglia and Joos, 2017). The seasonal cycle is dominated by fluxes from the land, in particular, the northern hemisphere. 

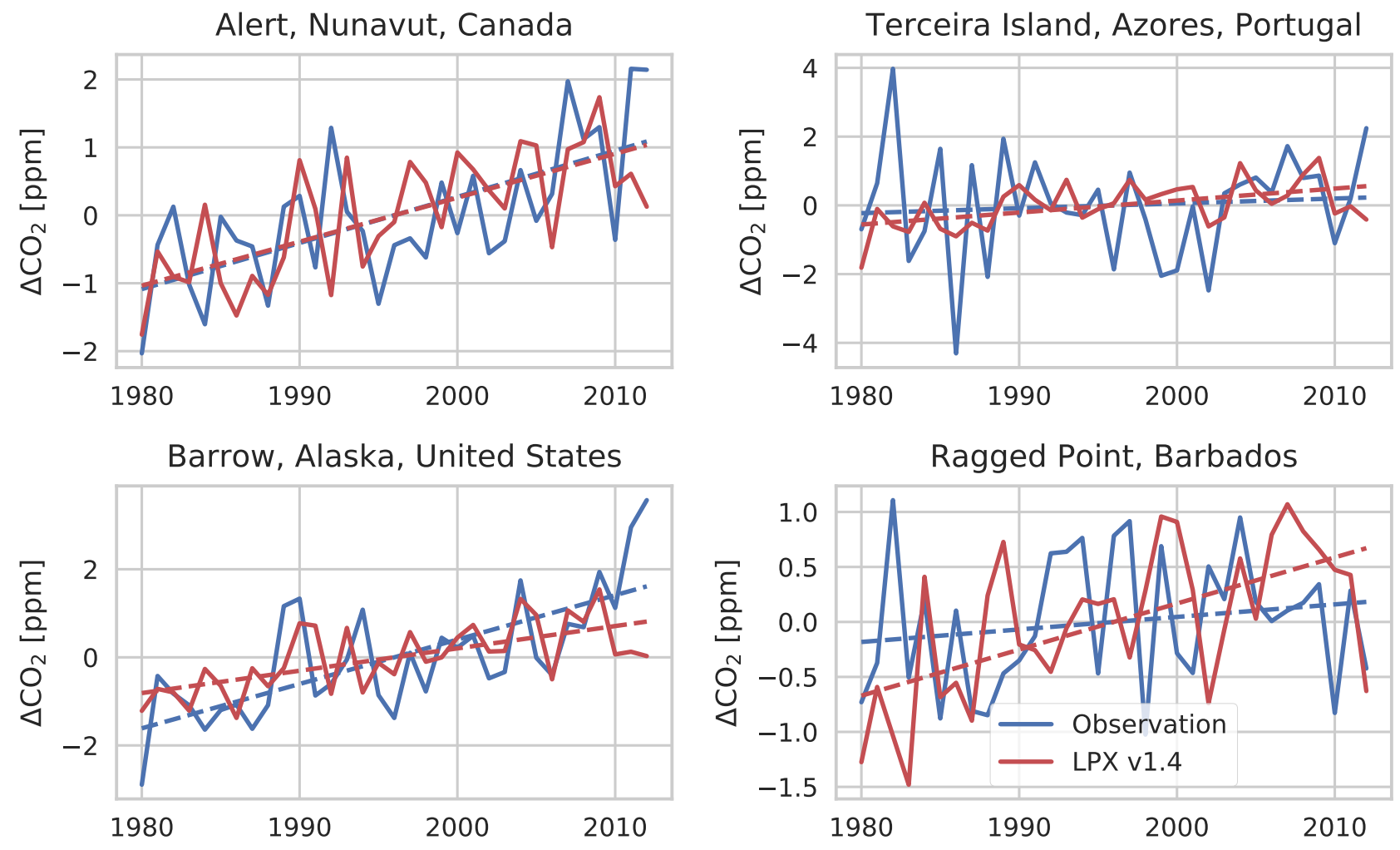

Figure S2. Growth in the amplitude of atmospheric $\mathrm{CO}_{2}$ for four measurement sites (GLOBALVIEW-CO2, 2013) (blue) compared to LPX v1.4 (red). A linear fit indicated by dashed lines is included. The growth in the amplitude of the seasonal cycle is computed with the TM2 transport model and simulated net surface-atmosphere fluxes from LPX v1.4 and the Bern3D ocean model (Battaglia and Joos, 2017). The seasonal cycle is dominated by fluxes from the land, in particular, the northern hemisphere.

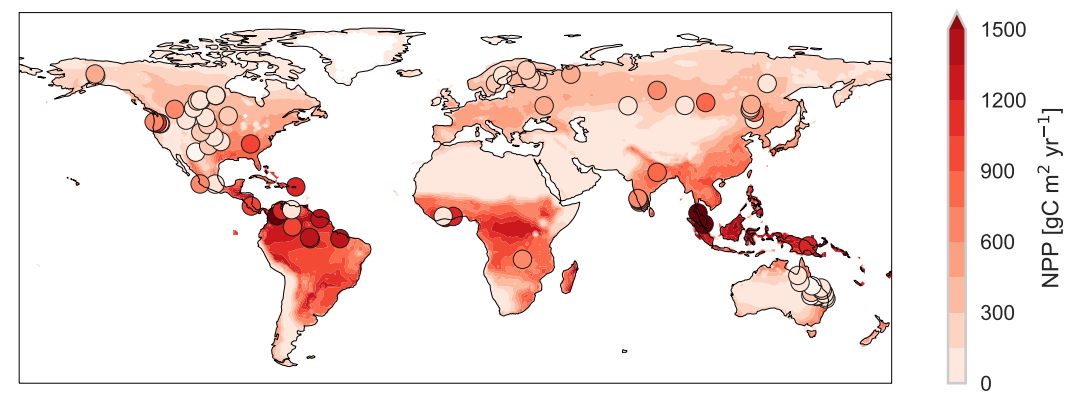

Figure S3. Comparison of annual NPP of LPX v1.4 with Multi-Biome NPP measurements sites (Olson et al., 2013) indicated with circles. The simulation results are averaged over the period of 1931-1997. 


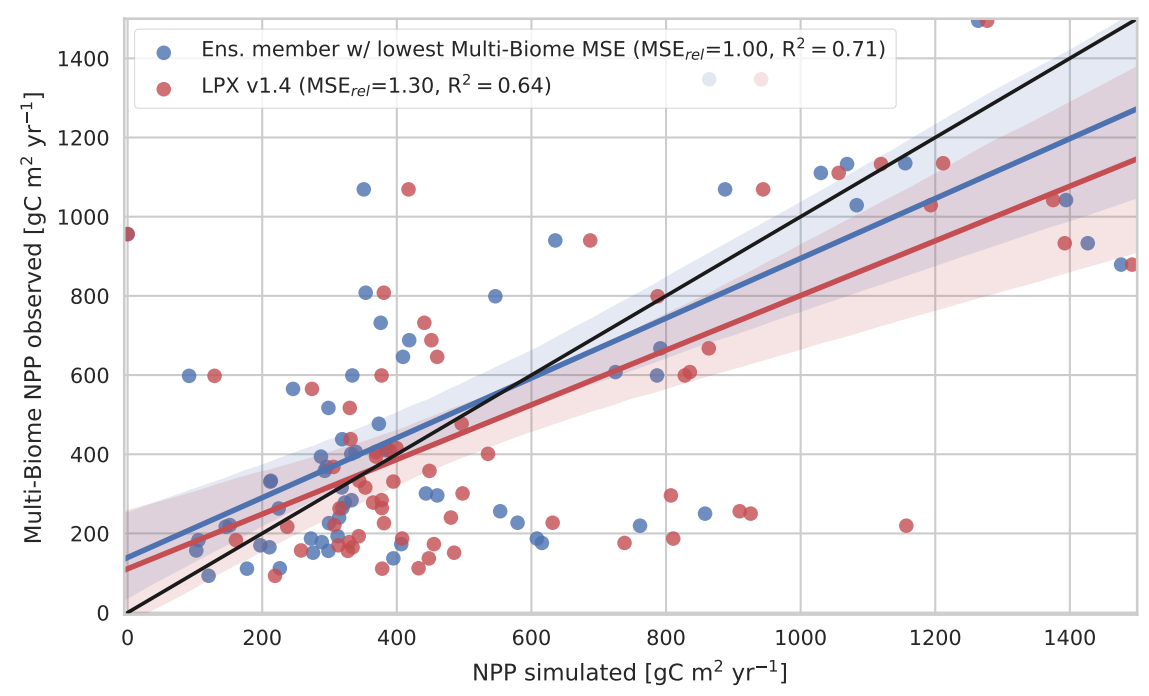

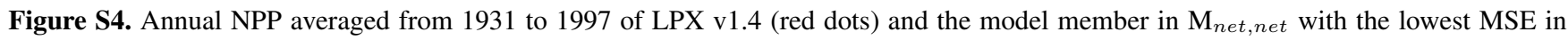
this metric (blue dots) against Multi-Biome NPP (Olson et al., 2013) estimates. The colored lines show a linear regression with the 95\% confidence interval shaded.

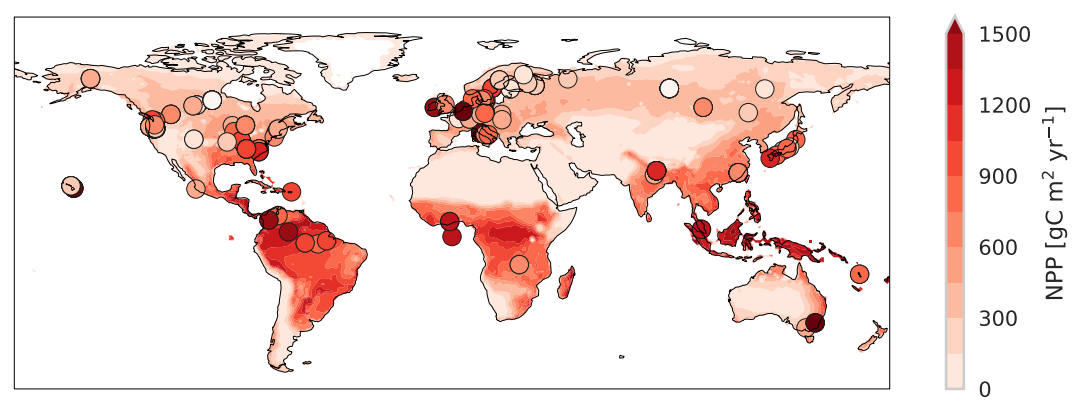

Figure S5. Comparison of annual NPP of LPX v1.4 with FLUXNET NPP measurements sites (Luyssaert et al., 2009, 2007) indicated with circles. The simulation results are averaged over the period of 1931-1997. 


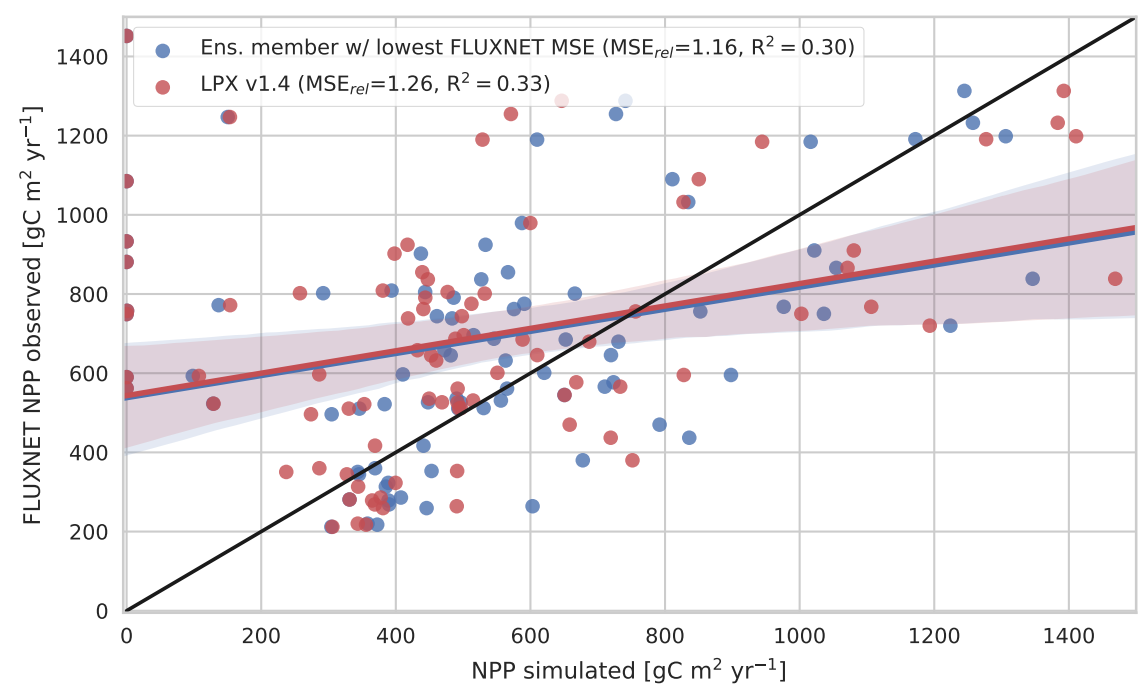

Figure S6. Annual NPP averaged from 1931 to 1997 of LPX v1.4 (red) and the model member in M $_{n e t, n e t}$ with the lowest MSE in this metric (blue) against FLUXNET NPP (Luyssaert et al., 2009, 2007) estimates. The colored lines show a linear regression with the 95\% confidence interval shaded. 


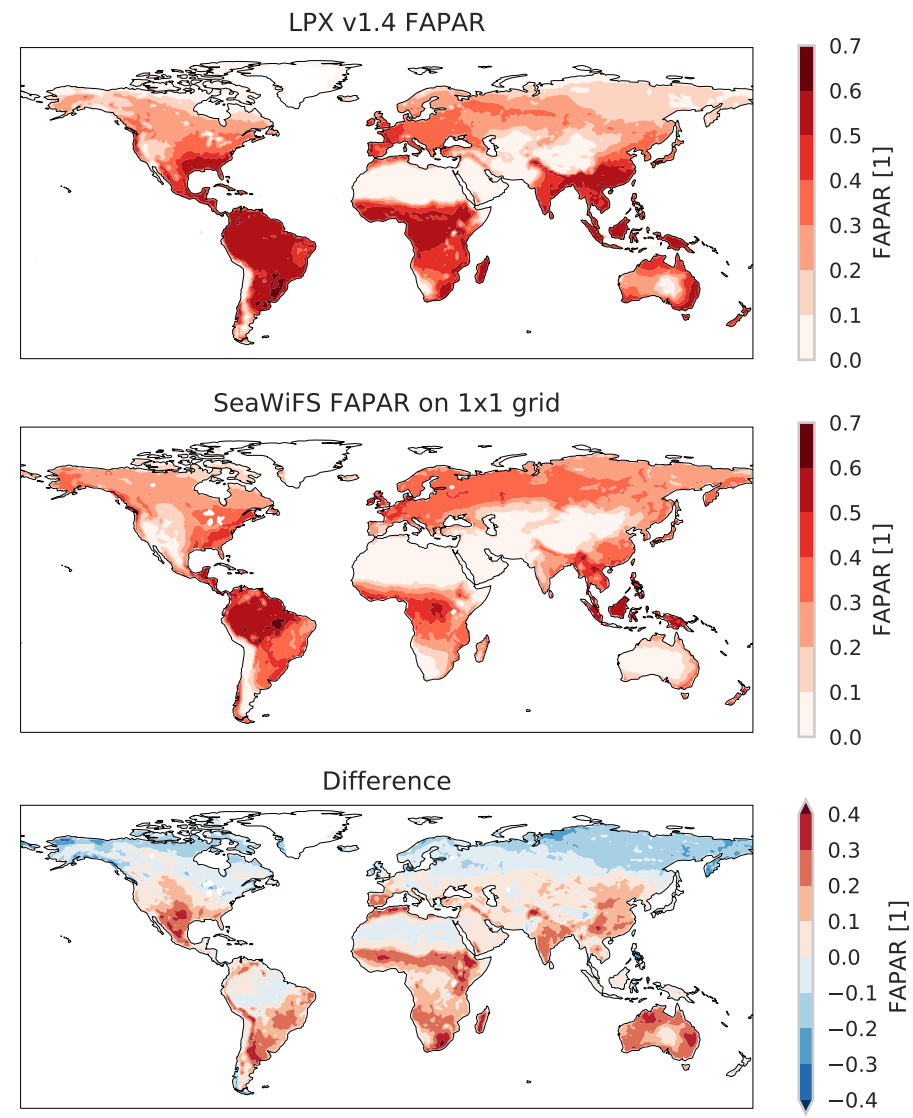

Figure S7. Fraction of absorbed photosynthetically active radiation (FAPAR) as simulated by LPX v1.4 (top panel) compared to a satellitederived product (Gobron et al., 2006) (middle panel) and the difference of the two products (bottom panel). Shown is the average from 09.1997 to 06.2006 , which has a correlation of $\mathrm{R}^{2}=0.65$. For the calculation of the MSE averaged monthly fields were used. 


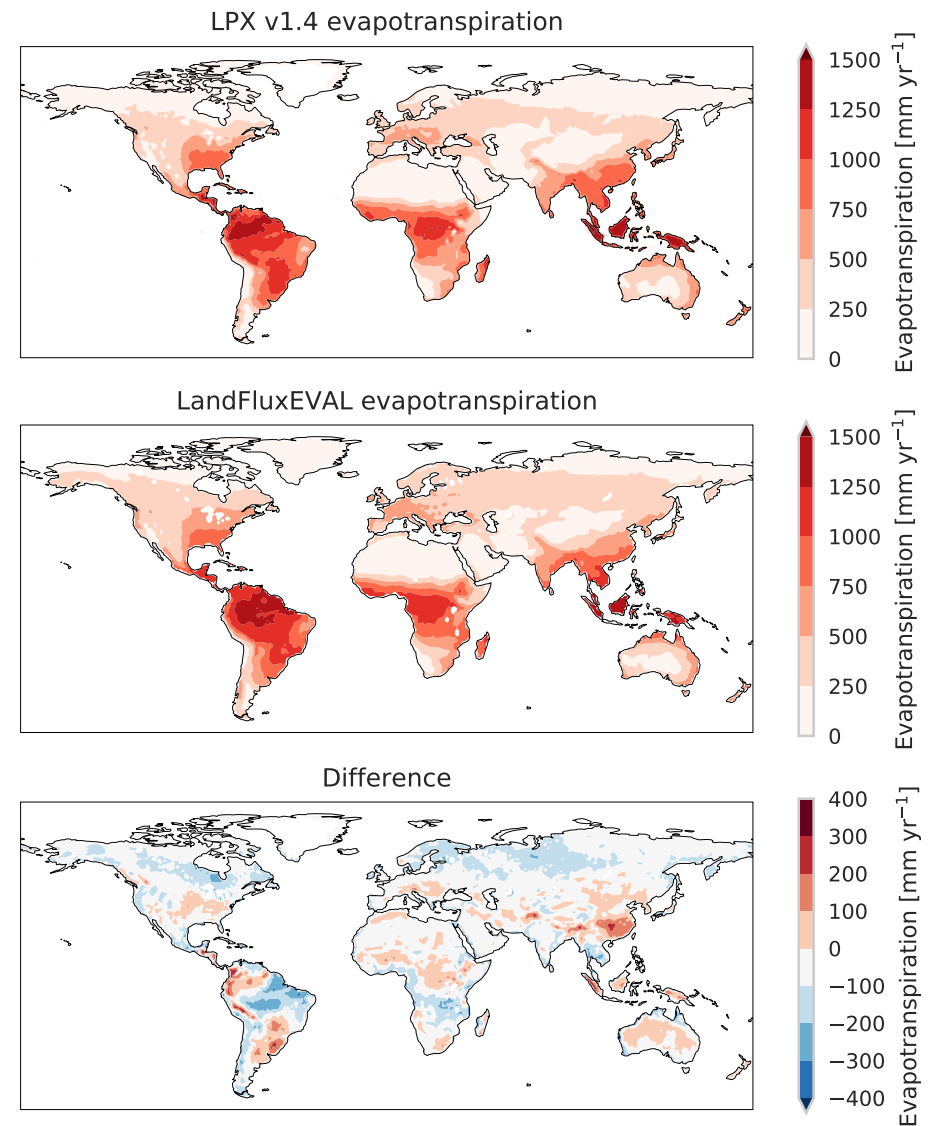

Figure S8. Evapotranspiration averaged from 1985 to 2005 as simulated by LPX v1.4 (top panel) compared to the LandFLUX-EVAL data product (Mueller et al., 2013) (middle panel) and the difference of the two products (bottom panel). The correlation of the two products is $\mathrm{R}^{2}=0.96$ 

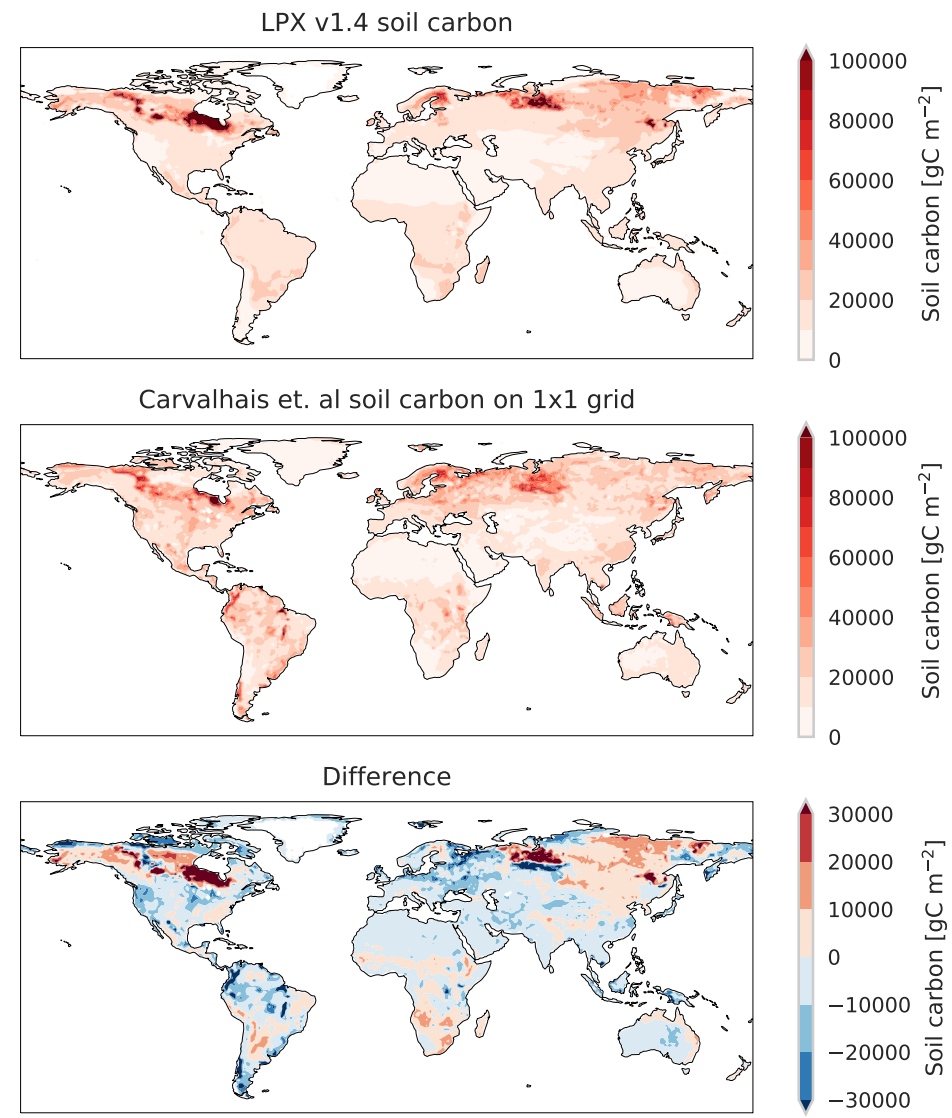

Figure S9. Soil carbon averaged from 1982 to 2005 as simulated by LPX v1.4 (top panel) compared to a dataset based on observations (Carvalhais et al., 2014) (middle panel) and the difference of the two products (bottom panel). The correlation of the two product is $\mathrm{R}^{2}=0.58$. For the calculation of the MSE the map is divided into low and high latitudes regions. 

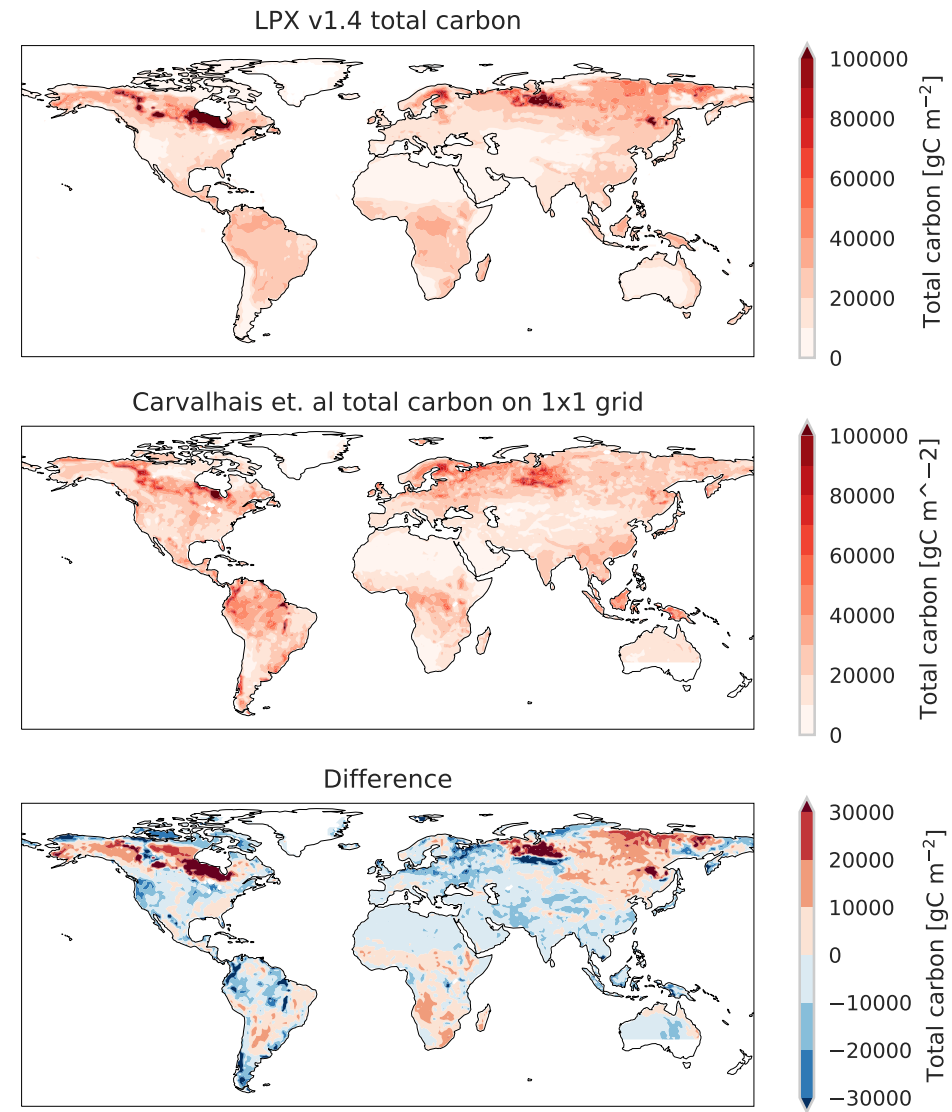

Figure S10. Total carbon (soil carbon and vegetation carbon) averaged from 1982 to 2005 as simulated by LPX v1.4 (top panel) compared to a dataset based on observations (Carvalhais et al., 2014) (middle panel) and the difference of the two products (bottom panel). The correlation of the two product is $\mathrm{R}^{2}=0.59$. 


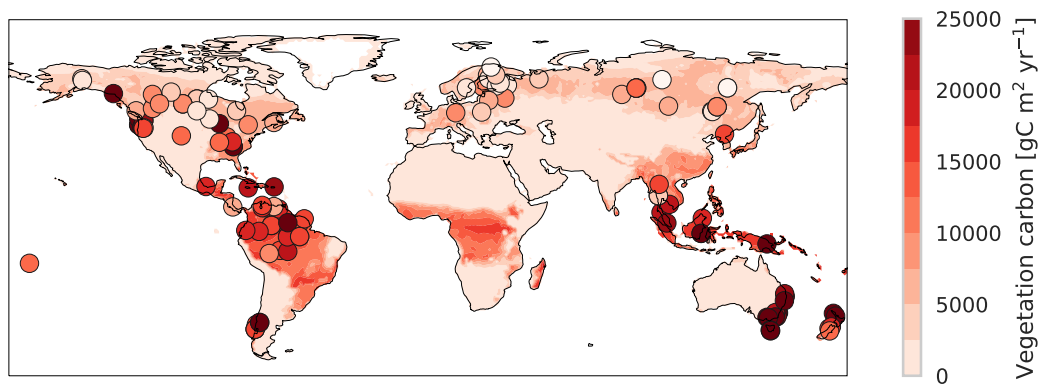

Figure S11. Vegetation carbon simulated by LPX v1.4 compared to local biomass measurements (circles) (Keith et al., 2009). The simulation results are averaged over the period of 1950-2000.

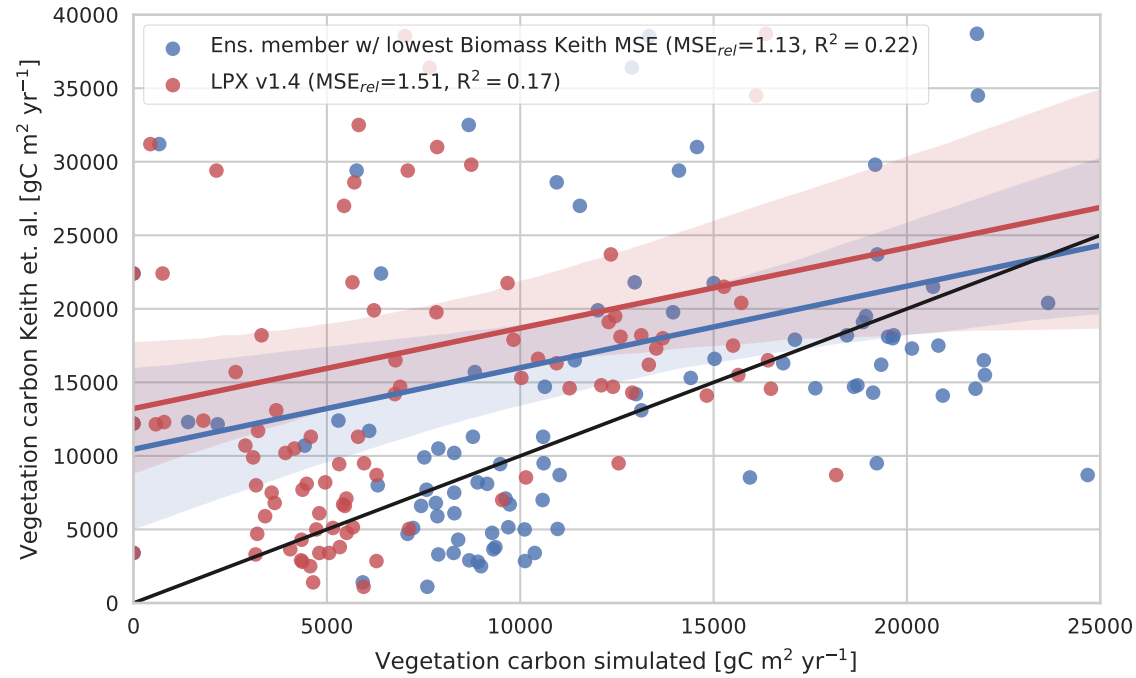

Figure S12. Vegetation carbon averaged from 1950 to 2000 of LPX v1.4 (red) and the model member in $\mathrm{M}_{n e t, n e t}$ with the lowest MSE in this metric (blue) against Keith et al. (2009) biomass estimates. The correlation would be enhanced when sites with zero simulated biomass were excluded (no effect on $\mathrm{MSE}_{r e l}$ ). The solid lines show a linear regression with the $95 \%$ confidence interval shaded. 


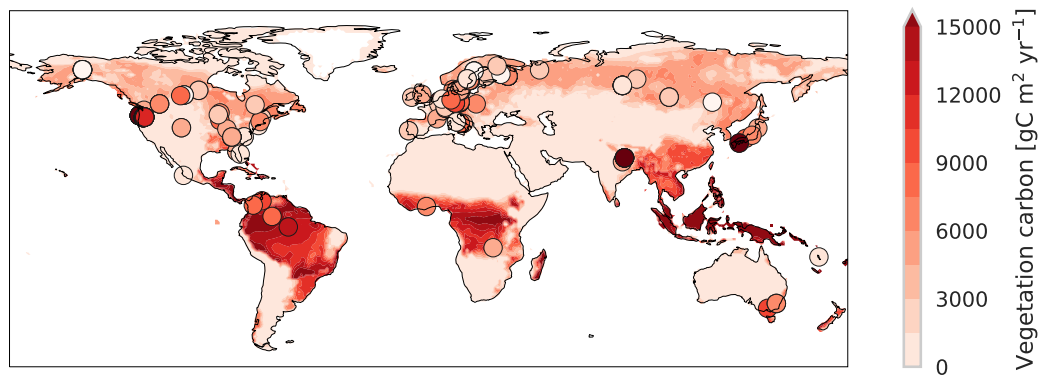

Figure S13. Vegetation carbon simulated by LPX v1.4 compared to local biomass measurements (circles) (Luyssaert et al., 2009, 2007). The simulation results are averaged over the period of 1931-2007.

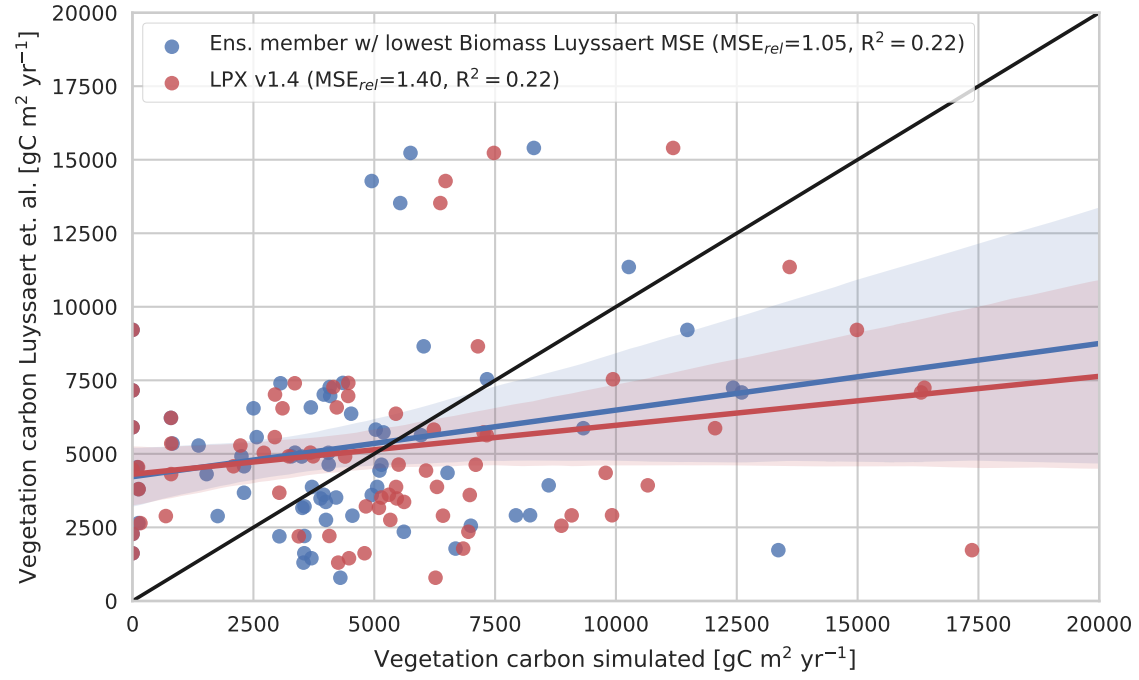

Figure S14. Vegetation carbon averaged from 1931 to 2007 of LPX v1.4 (red) and the model member in $\mathrm{M}_{n e t, n e t}$ with the lowest MSE in this metric (blue) against Luyssaert et al. $(2009,2007)$ biomass estimates. The correlation would be enhanced when sites with zero simulated biomass were excluded (no effect on $\mathrm{MSE}_{r e l}$ ). The solid lines show a linear regression with the $95 \%$ confidence interval shaded. 


\section{References}

Battaglia, G. and Joos, F.: Hazards of decreasing marine oxygen : the near-term and millennial-scale benefits of meeting the Paris climate targets, pp. 1-21, 2017.

Carvalhais, N., Forkel, M., Khomik, M., Bellarby, J., Jung, M., Migliavacca, M., Mgru, M., Saatchi, S., Santoro, M., Thurner, M., Weber, U., Ahrens, B., Beer, C., Cescatti, A., Randerson, J. T., and Reichstein, M.: Global covariation of carbon turnover times with climate in terrestrial ecosystems, Nature, 514, 213-217, https://doi.org/10.1038/nature13731, 2014.

GLOBALVIEW-CO2: Cooperative Global Atmospheric Data Integration Project. 2013, updated annually. Multi-laboratory compilation of synchronized and gap-filled atmospheric carbon dioxide records for the period 1979-2012 (obspack_co2_1_GLOBALVIEWCO2_2013_v1.0.4_2013-12-23)., 2013.

Gobron, N., Pinty, B., Aussedat, O., Chen, J. M., Cohen, W. B., Fensholt, R., Gond, V., Huemmrich, K. F., Lavergne, T., Mélin, F., Privette, J. L., Sandholt, I., Taberner, M., Turner, D. P., Verstraete, M. M., and Widlowski, J. L.: Evaluation of fraction of absorbed photosynthetically active radiation products for different canopy radiation transfer regimes: Methodology and results using Joint Research Center products derived from SeaWiFS against ground-based estimations, Journal of Geophysical Research Atmospheres, 111, https://doi.org/10.1029/2005JD006511, 2006.

15 Keith, H., Mackey, B. G., and Lindenmayer, D. B.: Re-evaluation of forest biomass carbon stocks and lessons from the world's most carbon-dense forests., Proceedings of the National Academy of Sciences of the United States of America, 106, 11635-11640, https://doi.org/10.1073/pnas.0901970106, http://www.ncbi.nlm.nih.gov/pubmed/19553199, 2009.

Luyssaert, S., Inglima, I., Jung, M., Richardson, A. D., Reichstein, M., Ppapale, D., Piao, S. L., Schulze, E. .-D. D., Wingate, L., Matteucci, G., Aragao, L., Aubinet, M., Beer, C., Bernhofer, C., Black, K. G., Bonal, D., Bonnefond, J. .-M. M. .-M., Chambers, J., Ciais, P., Cook, B., Davis, K. J., Dolman, A. J., Gielen, B., Goulden, M., Grace, J., Granier, A., Grelle, A., Griffis, T., Grünwald, T., Guidolotti, G., Hanson, P. J., Harding, R., Hollinger, D. Y., Hutyra, L. R., Kolari, P., Kruijt, B., Kutsch, W., Lagergren, F., Laurila, T., Law, B. E., Le Maire, G., Lindroth, A., Loustau, D., Malhi, Y., Mateus, J., Migliavacca, M., Misson, L., Montagnani, L., Moncrieff, J., Moors, E., Munger, J. W., Nikinmaa, E., Ollinger, S. V., Pita, G., Rebmann, C., Roupsard, O., Saigusa, N., Sanz, M. J., G., S., C., S., Smith, M. .-L. L., Tang, J., Valentini, R., Vesala, T., and Janssens, I. A.: CO2 balance of boreal, temperate, and tropical forests derived from a global database, Global Change Biol., 13, 2509-2537, https://doi.org/10.1111/j.1365-2486.2007.01439.x, 2007.

Luyssaert, S., Inglima, I., and Jung, M.: Global Forest Ecosystem Structure and Function Data For Carbon Balance Research, https://doi.org/10.3334/ORNLDAAC/949, 2009.

Mueller, B., Hirschi, M., Jimenez, C., Ciais, P., Dirmeyer, P. A., Dolman, A. J., Fisher, J. B., Jung, M., Ludwig, F., Maignan, F., Miralles, D. G., McCabe, M. F., Reichstein, M., Sheffield, J., Wang, K., Wood, E. F., Zhang, Y., and Seneviratne, S. I.: Benchmark products for land evapotranspiration: LandFlux-EVAL multi-data set synthesis, Hydrology and Earth System Sciences, 17, 3707-3720, https://doi.org/10.5194/hess-17-3707-2013, 2013.

Olson, R. J., Scurlock, J. M. O., Prince, S. D., Zheng, D. L., and Johnson, K. R.: NPP Multi-Biome: NPP and Driver Data for Ecosystem Model-data Intercomparison, R2, https://doi.org/10.3334/ornldaac/615, 2013. 